\title{
The Effect of Unilateral Naris Occlusion on Cell Dynamics in the Developing Rat Olfactory Epithelium
}

\author{
Albert I. Farbman, ${ }^{1}$ Peter C. Brunjes, ${ }^{2}$ Lauren Rentfro, ${ }^{1}$ James Michas, ${ }^{1}$ and Steven Ritz ${ }^{1}$ \\ 'Department of Neurobiology and Physiology, Northwestern University, Evanston, Illinois 60208, and 'Department of \\ Psychology, University of Virginia, Charlottesville, Virginia 22901
}

The effect of unilateral naris occlusion on the cellular dynamics of developing olfactory epithelium was investigated in postnatal rats. Nares of rat pups, at 1,5 , and $10 \mathrm{~d}$ postnatally, were cauterized; after a $30 \mathrm{~d}$ survival period, the olfactory mucosa was examined histologically, and quantitative estimates were made of total number of receptor neurons (together with basal cells), supporting cells, and epithelial thickness. In each group, there were significant differences between occluded and patent sides in total numbers of neurons and in epithelial thickness but no difference in number of supporting cells. The differences were greater in the animals that had been occluded for 1-30 d than in the 5-35 or 10-40 d groups, suggesting that the earlier postnatal days are more sensitive to the effects of occlusion. We evaluated the number of mature olfactory neurons by staining immunohistochemically with an antibody against olfactory marker protein. There were no differences in the number of mature receptor neurons between the occluded and nonoccluded sides, indicating the effect of naris occlusion was on the neurons in the immature and/or the "almost mature" population. Using ${ }^{3} \mathrm{H}$-thymidine autoradiography, we determined that there was a $40 \%$ reduction in the rate of neurogenesis in the animals occluded $1-30 \mathrm{~d}$ after birth. Further, the rate of cell proliferation in nasal respiratory epithelium declined by approximately the same amount. The results suggest that the changes in olfactory cell dynamics are probably the result of protective effect of naris occlusion, i.e., the prevention of infectious or toxic agents from entering the occluded side of the nasal cavity, rather than a change in the functional activity of olfactory receptor cells.

The effect of restricting sensory input on development of the olfactory system has been studied in neonatal and very young rodents. When one naris in a neonatal animal is experimentally occluded, and the animal is allowed to survive for $30 \mathrm{~d}$, the postnatal increase in size and weight of the ipsilateral olfactory bulb is significantly less than that of the bulb on the unoperated side (Meisami, 1976; Meisami and Safari, 1981; Brunjes and Borror, 1983; Benson et al., 1984; Brunjes, 1985; Brunjes et al., 1985; Skeen et al., 1985, 1986; Brunjes and Frazier, 1986). An examination of the time course of bulb changes in rats revealed

\footnotetext{
Received Aug. 24, 1987; revised Dec. 28, 1987; accepted Dec. 30, 1987.

This work was supported by NIH Grants NS 23348 and NS 23154. The authors are grateful for stimulating and helpful discussions with Dr. Bert Ph. M. Menco

Correspondence should be addressed to Dr. Albert I. Farbman at the above address.
}

Copyright (C) 1988 Society for Neuroscience $0270-6474 / 88 / 093290-06 \$ 02.00 / 0$ that differences in size could be seen as early as $11 \mathrm{~d}$ after occlusion (Brunjes, 1985).

Biochemical studies have shown that the bulbar volume change is accompanied by lower total protein, DNA, RNA, acetylcholinesterase, and sodium-potassium ATPase (Meisami and Mousavi, 1982). A reduction in total bulb dopamine content is detectable as early as $8 \mathrm{~d}$ after naris closure in neonates (Brunjes et al., 1985). Moreover, histochemical assays for succinic dehydrogenase and cytochrome oxidase showed that asymmetries in staining patterns are detcctable as carly as $4 \mathrm{~d}$ after unilateral naris occlusion (Cullinan and Brunjes, 1987). Even when naris occlusion was done in older animals, 4-9 weeks old, and continued for 10-14 d, a drastic reduction in the number of tyrosine hydroxylase immunoreactive elements in the glomerular layer of the bulb could be shown (Kosaka et al., 1987). These changes were somewhat reversible if the naris was reopened.

The profound effects of naris occlusion on the bulb suggested that changes might also occur in the primary olfactory receptor neurons in the nasal cavity. This had been examined by others, and no difference was found in the number of mature olfactory epithelial receptors between closed and open sides $30 \mathrm{~d}$ postoperatively (Benson et al., 1984). However, in a preliminary study, done simultaneously and independently in our laboratory, we found that, $30 \mathrm{~d}$ after unilateral occlusion in neonatal rats, there was indeed a reduction in number of olfactory neurons on the side ipsilateral to the occlusion but no change in number of supporting cells (Farbman et al., 1984). The present paper reports on the continuation of this study and further experiments done to try to resolve the conflict between our data and those of Benson et al. (1984).

\section{Materials and Methods}

Rats aged 1, 5, and $10 \mathrm{~d}$ old were used for these experiments. The right naris of experimental animals was occluded under light anesthesia by cautery. Thirty days layer, the animals were anesthetized with Nembutal and fixed by intracardiac perfusion with Bouin's mixture $(75 \%$ saturated picric acid, $20 \%$ formalin, $5 \%$ acetic acid) after flushing the circulation with PBS. The heads were removed, skinned, decalcified with RDO (Dupage Kinetics Lab, Inc., Naperville, IL), dehydrated, and embedded in paraffin. Littermates that had the cautery applied to the skin on the dorsal snout were used as controls. Five to six pairs of animals were used in each group. Animals displaying incomplete naris occlusion at time of sacrifice were discarded.

In another experiment, 1-d-old animals were treated as above and allowed to survive for 10 or $20 \mathrm{~d}$, anesthetized, and fixed by intracardiac perfusion as described.

Coronal sections, 7-8 $\mu \mathrm{m}$ thick, were cut and stained with hematoxylin and eosin. Five sections, separated from each other by $600-700$ $\mu \mathrm{m}$, were selected for cell counting from each subject. Regions of the right and left sides of the nasal septum were photographed and epithelial cell counts made on the photographs along a $200 \mu \mathrm{m}$ length of nasal 

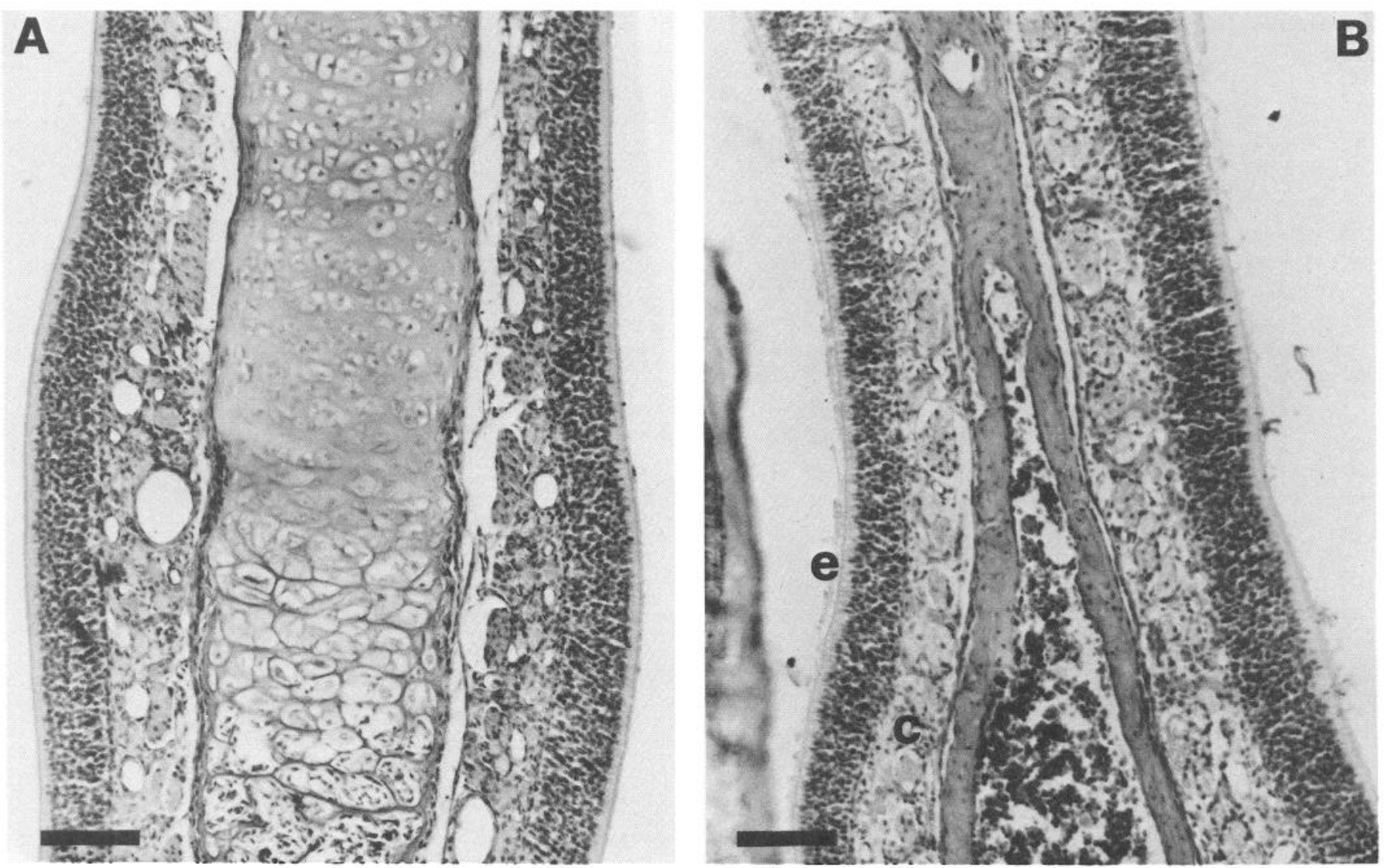

Figure 1. Photomicrographs of representative coronal sections through the nasal septum of control $(A)$ and occluded $(B)$ rats (occluded on the day of birth and killed at $30 \mathrm{~d})$. The thickness of both the epithelium $(e)$ and lamina propria $(c)$ on the occluded side $(B$, left) is noticeably less than that of the right side, and less than that seen in $A$. Scale bar, $100 \mu \mathrm{m}$.

septum. For the operated animals, the left side served as a control for the occluded right side in the same section.

Counts were made of (1) combined number of basal and receptor cell nuclei (because it was not always possible to distinguish between nuclei of basal cells and those of deep-lying receptor cells, these 2 populations were considered together; see Costanzo and Graziadei, 1983); (2) number of supporting cell nuclei; and (3) measurements of epithelial thickness (measured at 3 points on each $200 \mu \mathrm{m}$ length of epithelium in a section, and averaged; the points where Bowman's gland ducts penetrated the epithelium were avoided in thickness measurements). All animals exhibiting rhinitis (as a cellular or amorphous exudate) on either side of the nasal cavity were discarded.

Immunohistochemistry. Sections were deparaffinized to water, and the Sternberger (1977) PAP procedure was used to demonstrate olfactory marker protein, as described in an earlier paper (Farbman and Margolis, 1980). Briefly, sections were incubated in a 1:1 mixture of normal rabbit serum: $0.1 \mathrm{~m}$ phosphate buffer, $\mathrm{pH} 7.2$, for $10 \mathrm{~min}$, then sequentially, in a 1:200 dilution of antibody to OMP (a gift of Dr. Frank Margolis, Roche Institute of Molecular Biology, Nutley, NJ), a 1:50 dilution of rabbit anti-goat serum, and a 1:200 dilution of goat serum conjugated to peroxidase-antiperoxidase, all at $37^{\circ} \mathrm{C}$. After each antiserum treatment there was a $10 \mathrm{~min}$ wash with phosphate buffer at room temperature. Specimens were then incubated for $5 \mathrm{~min}$ at room temperature in a freshly made solution containing $0.3 \mathrm{ml}$ of $3 \%$ hydrogen peroxide and $50 \mathrm{mg}$ of $3,3^{\prime}$-diaminobenzidine $\mathrm{HCl}$ in $100 \mathrm{ml}$ of Tris buffer, $\mathrm{pH}$ 7.2. This was followed by washing in running water, treatment with $1 \%$ osmium tetroxide for $30 \mathrm{sec}$ and mounting in glycerogel.

The numbers of OMP-positive olfactory knobs were counted along a $200 \mu \mathrm{m}$ length of nasal septum, using a $100 \times$ oil-immersion lens on a Leitz Diavert microscope.

Autoradiography. Neonatal animals that had been cauterized as described above were allowed to survive for $30 \mathrm{~d}$ and given 3 injections of ${ }^{3} \mathrm{H}$-thymidine $(20 \mathrm{Ci} / \mathrm{mm}$ specific activity) at $8 \mathrm{hr}$ intervals $(4: 00$ p.m., midnight, and 8:00 a.m.). Two hours following the third injection the animals were anesthetized with Nembutal and perfused with Bouin's solution; the heads were processed for histological sectioning as described above. Sections were deparaffinized and coated with NTB-2 emulsion (Eastman Kodak, Rochester, NY), and the slides were placed in light-tight boxes in the refrigerator for 14-21 d. Slides were developed in Dektol, fixed, and stained with hematoxylin and eosin. Cells in the basal layer of olfactory epithelium that had been labeled with silver grains were counted along a $200 \mu \mathrm{m}$ length of the nasal septum on both the occluded and nonoccluded side. Nonoperated littermates were used as controls. All data were analyzed by the Student $t$ test.

\section{Results}

Figure $1, A, B$, shows typical sections of nasal septum from a control animal and one that had been unilaterally occluded as a neonate and killed $30 \mathrm{~d}$ later. It is clear from these photomicrographs that not only is the epithelium on the occluded side thinner and less cellular than that on the nonoccluded side, but the lamina propria is also thinner. Inspection of the data revealed there were no differences in cell counts from the various anterior-posterior levels within each animal to suggest a gradient of deprivation-induced effects. Accordingly, the data from the 5 anterior-posterior levels were grouped together for every animal. The results are expressed as ratios of cell counts, i.e., right/left sides, in both occluded and control subjects. In all age groups, counts on right and left sides in the control animals did not differ, nor did these values diverge from those on the nonoccluded (left) side of the operated animals, indicating no laterality in normal development, and that the occlusion procedure did not have effects on the contralateral side. 


\begin{tabular}{|c|c|c|c|}
\hline Group & Neurons & $\begin{array}{l}\text { Support- } \\
\text { ing cells }\end{array}$ & Thickness \\
\hline 1-10 Occluded & 0.98 & 1.00 & 0.98 \\
\hline Control & 1.03 & 1.02 & 0.98 \\
\hline 1-20 Occluded & 0.92 & 1.01 & $0.86(p<0.05)$ \\
\hline Control & 1.01 & 1.00 & 0.95 \\
\hline 1-30 Occluded & $0.82(p<0.002)$ & 0.98 & $0.89(p<0.0001)$ \\
\hline Control & 1.04 & 1.03 & 1.07 \\
\hline 5-35 Occluded & $0.87(p<0.01)$ & 0.95 & $0.80(p<0.002)$ \\
\hline Control & 0.99 & 1.01 & 0.94 \\
\hline 10-40 Occluded & $0.91(p<0.002)$ & 1.06 & $0.82(p<0.003)$ \\
\hline Control & 1.08 & 1.06 & 0.98 \\
\hline
\end{tabular}

Differences between left and right sides in occluded animals were not significant unless indicated with a $p$ value. Right-left differences in control animals were not significant in all cases.

The neuronal and basal cells, counted together, consistently made up $82-84 \%$ of the total epithelial cell population in control animals at all ages examined; supporting cells made up the remainder. In this study the numbers of olfactory cells and of supporting cells in a $200 \mu \mathrm{m}$ length of septum did not change significantly with age between postnatal days 10 and 40 . The average number of neuronal cells on the left side of the nasal cavity of 51 of the animals used in this study was 228.41 ( \pm 32.53 SD); supporting cells numbered $46.51( \pm 7.59)$.

In the 30-d-old animals that had been unilaterally occluded the right/left ratio of olfactory cell nuclei was 0.82 , indicating a significant difference between the 2 sides $(t=-6.831, p<$ 0.002 ; Table 1, Fig. 2). Moreover, the measured thickness of the epithelium on the deprived side was $11 \%$ less than that on the nondeprived side $(t=-8.723, p<0.0001)$. There were no differences in the number of supporting cells between right and left sides in operated animals.

Studies on olfactory bulb indicate that similar reductions in bulb size occur whether occlusion was done at 1 or $10 \mathrm{~d}$ of age, followed by a survival time of $30 \mathrm{~d}$. We were interested in determining whether the epithelial response to occlusion would parallel the bulbar changes. The ratios indicate that there were significantly fewer cells on the occluded side than on the nonoccluded side. For the 5-35 group, the ratio was $0.87(t=$ $-3.978, p<0.01)$; for the $10-40$ group, the ratio was $0.91(t$ $=-4.718, p<0.002$ ) (Table 1). Differences in epithelial thickness ratios between experimental and control animals in the 535 and $10-40 \mathrm{~d}$ groups were also significant (for the 5-35 group, $t=-5.748, p<0.002$; for the $10-40$ group, $t=-4.496, p<$ 0.003 ).

In earlier studies, anatomical differences could be detected in the olfactory bulb as early as $11 \mathrm{~d}$ after occlusion (Brunjes, 1985). We were interested in knowing whether changes in the epithelium occurred as early as those in the bulb, i.e., whether reduced numbers of receptor neurons would be detectable carlicr than $30 \mathrm{~d}$. We counted the olfactory cells in 10- and 20-d-old animals that had been unilaterally occluded as neonates. As shown in Figure 2 (Table 1), there were no detectable differences in olfactory neuron number in either group. In animals that had undergone unilateral naris occlusion as neonates, the reduction in neuron number was not expressed until $30 \mathrm{~d}$ after birth. There was, however, a difference in thickness of epithelium on the deprived side in the $20 \mathrm{~d}$ group (ratio $=0.86, t=-2.283, p<$
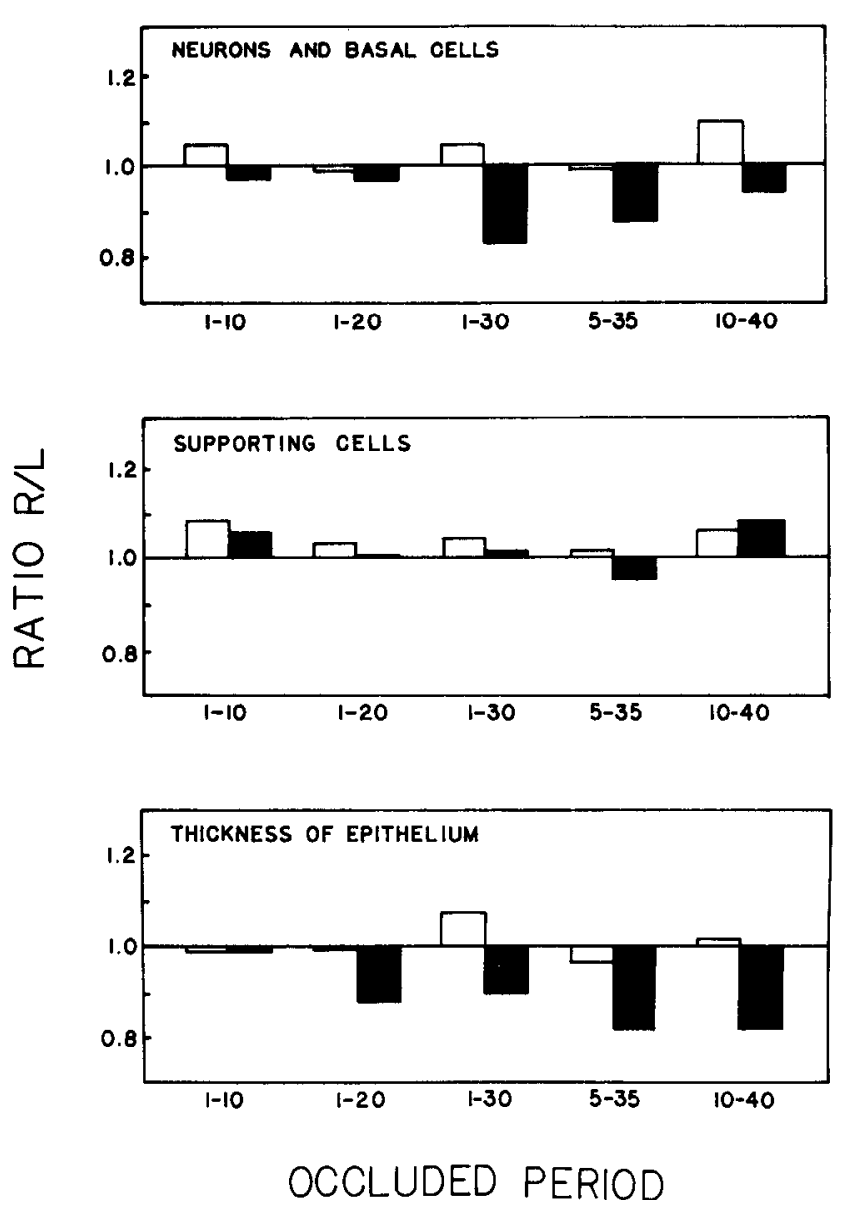

Figure 2. Graphic representation of the ratios of neuronal plus basal cell numbers, supporting cell numbers, and total epithelial thickness in the various groups of animals studied in these experiments. On the $x$-axis are the postnatal ages during which the animals were occluded and sacrificed. Open bars represent control animals; filled bars, unilaterally occluded animals. Standard errors ranged from 0.01 to 0.05 .

0.05). The reduction in thickness associated with no change in total numbers of cells suggested a reduction in size (length) of individual cells. Figure 3 is a photomicrograph of a nasal septum from an animal that had been unilaterally occluded as a neonate and killed at $20 \mathrm{~d}$. The difference in epithelial thickness between the 2 sides is apparent from this micrograph.

\section{Immunohistochemical staining of mature receptor cells}

Counts of OMP-positive dendritic knobs in control and unilaterally deprived animals were used as a measure of the numbers of mature receptor cells in the epithelium (Farbman and Margolis, 1980; Monti Graziadei et al., 1980; Allen and Akeson, 1985). This marker protein is expressed in olfactory neurons about 7-8 d after cell division (Miragall and Monti Graziadei, 1982), and therefore, one would not expect to see it in immature cells within the epithelium. Two to five sections were examined from different anterior-posterior levels in each head. The numbers of OMP-positive dendritic knobs on the occluded and nonoccluded sides were not different from each other (Table 2). That is, the ratios between right and left sides in both groups were essentially identical. In 8 control animals (a total of 39 sections), the right/left ratio was 0.99 ; in unilaterally occluded animals, it was 1.02 (6 animals, a total of 30 sections). 


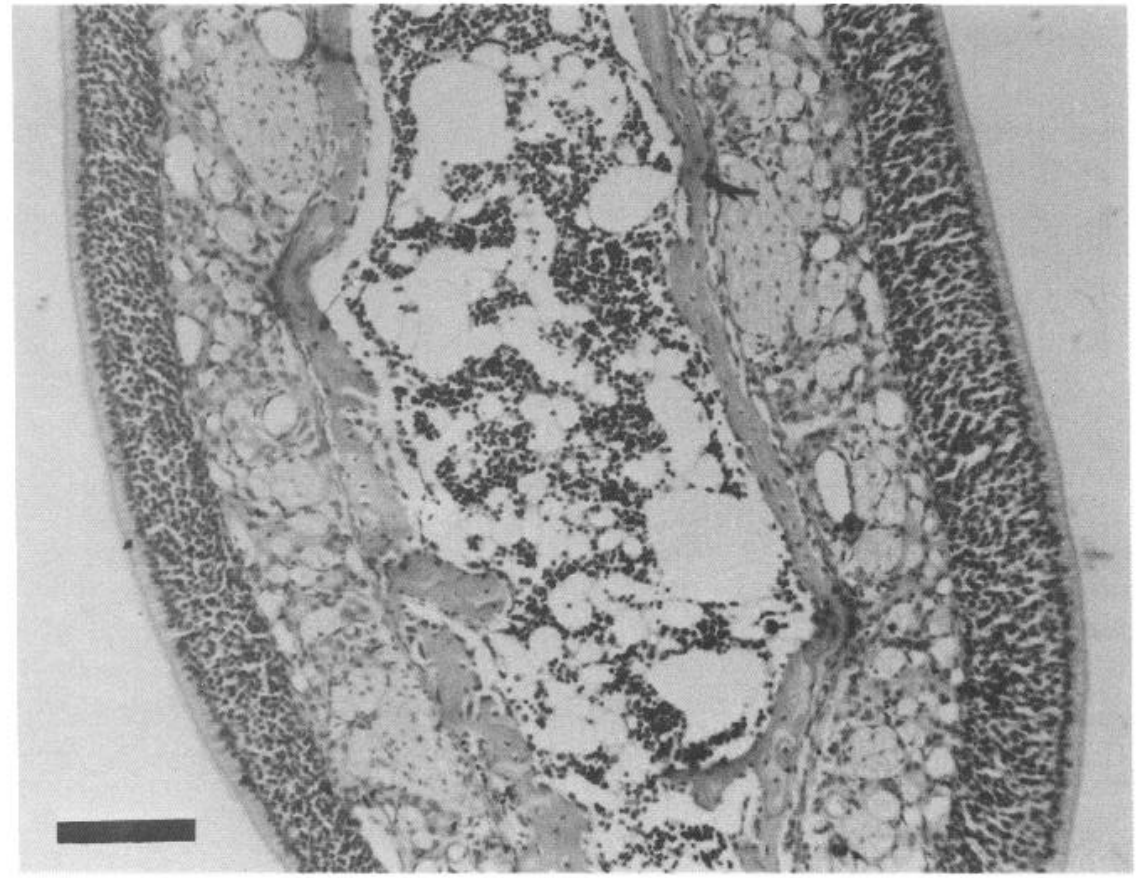

Figure 3. Photomicrograph of a nasal septum from a rat that had been unilaterally occluded as a neonate and sacrificed at $20 \mathrm{~d}$. The thickness of the epithelium on the left side of the photograph is clearly less than that on the right. Scale bar, $100 \mu \mathrm{m}$.

\section{Autoradiography}

Examination of sections from 1-30 animals that had received ${ }^{3} \mathrm{H}$-thymidine on day 30 showed that, while no right/left differences were encountered in control animals, significantly fewer basal cells on the occluded side had incorporated the DNA precursor. The ratio of labeled basal cells in the experimental group was $0.59(t=-5.6805, p<0.001)$, a clear indication that the rate of neurogenesis on the occluded side was reduced as a result of naris closure. However, the number of labeled cells on the nonoccluded side was similar to that on the right and left sides of unoperated control animals. Thus, there was no evidence that unilateral naris occlusion affected the rate of neurogenesis on the contralateral side.

In order to determine whether there was a reduction in cellular proliferation in the nonolfactory epithelium of the occluded nasal cavity, we examined uptake of ${ }^{3} \mathrm{H}$-thymidine in the respiratory epithelium on some of our autoradiographic slides. In occluded animals, the mean right/left ratio of ${ }^{3} \mathrm{H}$-thymidinelabeled cells, determined along a $400 \mu \mathrm{m}$ length of respiratory epithelium on the nasal septum, was $0.65( \pm 0.18, n=5)$, a value very close to that found in olfactory epithelium.

\section{Discussion}

Our results clearly show that unilateral occlusion of a naris for $30 \mathrm{~d}$ in newborn rats results in a reduction in the total number

Table 2. OMP-positive dendritic knobs in 30-d-old animals

\begin{tabular}{lll} 
Group & Number & Ratio \\
\hline Experimental $(n=6)$ & & \\
$\quad$ Occluded side (R) & $32.2 \pm 2.4$ & \\
$\quad$ Nonoccluded side (L) & $31.6 \pm 2.3$ & 1.02 \\
Control $(n=8)$ & & \\
$\quad$ Right side & $31.9 \pm 2.6$ & \\
Left side & $32.1 \pm 1.7$ & 0.99 \\
\hline
\end{tabular}

of olfactory neurons on the ipsilateral side but no change in the number of supporting cells. Although the total number of neurons is reduced, the number of mature dendritic knobs is unchanged (see Benson et al., 1984), suggesting that the reduction in neuronal population is at the expense of immature olfactory cells. Autoradiographic studies of animals that had been injected with ${ }^{3} \mathrm{H}$-thymidine after $30 \mathrm{~d}$ of occlusion showed that the affected epithelium exhibits fewer cells in DNA synthesis than the control; in other words, unilateral nasal closure resulted in a reduced amount of neurogenesis. Taken together, reduced neurogenesis in the olfactory neuronal population, coupled with no change in the number of mature cells or of supporting cells, and a reduction in the number of immature cells, suggests the neuronal cells in the population on the occluded side live longer.

In our studies using a $30 \mathrm{~d}$ postoperative survival period, the reduction in olfactory receptor cell number is more pronounced if the occlusion is done on the day after birth than if done 5 or $10 \mathrm{~d}$ later, suggesting that there is a sensitive period in postnatal development of the olfactory epithelium during which it responds more rapidly to naris occlusion. There was a significant difference between the right/left ratios of neurons and basal cells in the 1-30 d group and the 10-40 d group $(t=-2.433, p<$ $0.04)$. This indicated that the earlier the occlusion was performed, the greater the effect it had on cell dynamics.

We suggest the changes within the olfactory epithelium (on the nasal septum) resulting from unilateral occlusion probably proceed along the following time course. The earliest change is Table 3. Ratios (right/left) of ${ }^{3} \mathrm{H}$-thymidine-labeled basal cells in
olfactory epithelium of 30 -d-old animals

\begin{tabular}{ll} 
Group & Ratio \\
\hline Unilaterally occluded $(n=10)$ & $0.59^{a}$ \\
Unoperated $(n=8)$ & 1.01 \\
\hline${ }^{a} p<0.001(t=-5.6805)$. &
\end{tabular}


a reduction in size of cells, observed in the 1-20 d group as a decrease in total epithelial thickness accompanied by a slight, but not significant decrease in cell number. This is followed by a reduction in the rate of DNA synthesis in the basal cells, resulting in fewer new neurons being produced. Throughout this period, the number of mature neurons is maintained at a steady state. With a decline in neurogenesis and a reduction in the immature fraction of olfactory receptor cells, the population dynamics of the epithelium approach a new equilibrium.

The phenomenon of continued neurogenesis in olfactory epithelium throughout life is well known (reviewed by Graziadei and Monti Graziadei, 1978). During normal development from neonate to adult there is a reduction in number of dividing cells in the olfactory epithelial compartment and an age-related increase in the ratio of intermediate or "almost mature" cells to mature cells within a given area (Breipohl et al., 1986). In other words, receptor cells in older animals spend a longer time in the differentiation phase of their life cycles. The increased number of "almost mature" cells results in an increase in epithelial thickness. According to a recently articulated hypothesis of the cellular dynamics of the olfactory epithelium, these intermediate cells play an important role in the regulation of the olfactory neuronal population (Breipohl et al., 1986). An almost mature cell may quickly replace a mature receptor cell that dies as a result of injury of some sort or it may itself die before becoming mature because of the absence of a site in the olfactory bulb with which it can form a synapse, a common cause of cell death in many regions of the developing nervous system.

In our experimental system, the reduced mitotic activity is accompanied by a thinning of the epithelium, at least in the 30 d experimental period. This reduction in thickness, accompanied by a slight change in the number of mature receptor neurons, comes about at the expense of the "almost mature" or intermediate population. This must mean that under the experimental conditions, the response to unilateral naris closure is a sidestepping of the normal differentiative process, because the requirement for a sizable intermediate population is obviated by the naris closure and resultant deprivation of airflow and sensory input. We predict these conditions permit the mature olfactory receptor cells to live considerably longer than normal, as has been shown when animals are reared in a filtered air environment (Hinds et al., 1984).

If unilateral naris occlusion leads to a diminished rate of neurogenesis in the epithelium, and a reduction in the number of receptor neurons, does this come about because of sensory deprivation or because closure of the nostril protects the nasal mucosa against environmental insults? Naris closure reduces the amount of sensory input in olfactory epithelium, although not to zero because some input undoubtedly reaches the receptor neurons via the nasopharynx and via some mixing of air between the 2 sides through a window in the septum usually found in rodents. It is possible that the results could be explained by a relationship between the mitogenic stimulus and the reduced functional activity of the neurons. However, blocking the frec movement of air through one side of the nasal cavity also results in the protection of the epithelium from drying and from the effects of airborne pollutants or potential cytotoxic agents and inhibits the entrance into the nasal cavity of infectious organisms from the environment. In a study on mice, it was found that neurogenesis in the olfactory epithelium was reduced and receptor cells lived much longer when the animals were kept in an environment in which the air was filtered (Hinds et al., 1984).
In that study, the inference was made that rhinitis might be an important factor in loss of olfactory cells. Further, the authors suggested that the evolutionary advantage of a continual production of receptors is to protect against disease-related impairment of smell consequent to loss of receptor cells. It is possible that unilateral occlusion protected the closed nasal cavity against rhinitis. In support of this notion was our observation that in those animals discarded from this study because of rhinitis, the exudate was invariably found in the open side.

Others have studied the effects of unilateral nasal occlusion on respiratory epithelium in the nasal cavity and found changes in this epithelium as well-an increase in goblet cells and a decrease in ciliated cells (Hilding, 1932; Mogensen and Tos, 1979). Although quantitative estimates of the changes were not provided in those studies, they do support the notion that the reduction in airflow can bring about changes in other parts of the nasal cavity. Our data have shown that naris occlusion results in essentially similar reductions in the rates of cellular proliferation in both olfactory and respiratory epithelia, thus adding support to the notion that the mitogenic stimulus is more probably related to the protective effect of airflow reduction consequent to nasal closure rather than anything peculiar to the functional activity of receptor cells.

The time course of changes within the epithelium following unilateral naris occlusion does not parallel that in the bulb. In the bulb, differences in size between normal and occluded sides were first detectable $11 \mathrm{~d}$ after occlusion, when the bulbs were $10 \%$ smaller (Brunjes, 1985). In the epithelium, we saw no reduction in size until $20 \mathrm{~d}$ after occlusion. In the bulb, occlusion on either postnatal day 1 or 10 , followed by a $30 \mathrm{~d}$ survival period has virtually the same effect, namely, a $25 \%$ decrease in bulb volume on the ipsilateral side, but occlusion on postnatal day 20 has a lesser effect. It has been suggested that deprivation effects in the bulb are not due simply to atrophy resulting from receptor inactivation but must be related to an interaction between experiential and developmental processes (Brunjes and Frazier, 1986). In our studies, occlusion on postnatal day 10 , followed by a 30 d survival period (10-40) had a significantly lesser effect on the epithelium than occlusion on day 1 . However, because there was a reduction in epithelial thickness in this experimental group, it is probable that a longer survival period would lead to reduction in cell numbers, as seen in the $1-30 \mathrm{~d}$ animals.

In an earlier analysis, Benson et al. (1984) assumed that the number of dendritic knobs in the olfactory epithelium represented the number of mature receptor cells, and implied that only mature receptor cells project to the olfactory nerve layer in the bulb. They found no difference in number of dendritic knobs between control and occluded sides (which we corroborated in our counts of OMP-positive knobs), but they did note a $15 \%$ reduction in volume of the olfactory nerve layer in the bulb ipsilateral to the occlusion. They tried to explain the apparent contradiction by (1) a possible reduction in blood supply, (2) a possible reduction in diamcter of axons, or (3) possibly shorter axons. None of these explanations could be documented.

The data from that study and ours can be explained by the fact that olfactory receptor cells, like other neurons, grow an axon before their dendrite matures. In serial developmental studies, it has been shown that the olfactory axons of receptor cells reach the bulb before the dendritic knob expresses secondary cilia, i.e., before the dendrite matures (Cuschieri and Bannister, 1975; Farbman and Squinto, 1985; Menco and Farb- 
man, 1985). Consequently, one might expect to find that a diminished volume in the olfactory nerve layer is accompanied by a reduction in the population of less mature epithelial cells because even thesc less mature cells, i.e., those lacking a mature dendritic knob, project axons and thus contribute to the olfactory nerve layer. A close inspection of Figure 1 in the paper by Benson et al. (1984) and a direct count of the total number of epithelial cell nuclei along a $200 \mu \mathrm{m}$ length of septum in that photomicrograph makes it apparent that there is a real difference of about $20 \%$ between control and occluded side in their material as well. If this pholomicrograph is representative of their data on occluded mouse nares, the data in our study and theirs, with respect to total number of olfactory epithelial cells and the number of mature neurons, are in agreement.

In conclusion, our data show that unilateral naris occlusion results in a change in the cell dynamics of the neuronal population in rodent olfactory epithelium. The change is more pronounced if closure is done the day after birth than later. The nature of the change in equilibrium suggests that the consequence of occlusion is longer-lived olfactory receptor cells, probably as a result of protection against rhinitis.

\section{References}

Allen, W., and R. Akeson (1985) Identification of an olfactory receptor neuron subclass: Cellular and molecular analysis during development. Dev. Biol. 109: 393-401.

Benson, T. E., D. K. Ryugo, and J. W. Hinds (1984) Effects of sensory deprivation on the developing mouse olfactory system: A light and electron microscopic, morphometric analysis. J. Neurosci. 4: 638653.

Breipohl, W., A. Mackay-Sim, D. Grandt, B. Rehn, and C. Darrelmann (1986) Neurogenesis in the vertebrate main olfactory epithelium. In Ontogeny of Olfaction, W. Breipohl, ed., pp. 21-33, Springer-Verlag, Berlin.

Brunjes, P. C. (1985) Unilateral odor deprivation: Time course of changes in laminar volume. Brain Res. Bull. 14: 233-237.

Brunjes, P. C., and M. J. Borror (1983) Unilateral odor deprivation: Differential effects due to time of treatment. Brain Res. Bull. 11: 501503.

Brunjes, P. C., and L. L. Frazier (1986) Maturation and plasticity in the olfactory system of vertebrates. Brain Res. Rev. 11: 1-45.

Brunjes, P. C., L. K. Smith-Crafts, and R. McCarty (1985) Unilateral odor deprivation: Effects on the development of olfactory bulb catecholamines and behavior. Dev. Brain Res. 22: 1-6.

Costanzo, R. M., and P. P. C. Graziadei (1983) A quantitative analysis of changes in the olfactory epithelium following bulbectomy in hamster. J. Comp. Neurol. 215: 370-381.

Cullinan, W. E., and P. C. Brunjes (1987) Unilateral odor deprivation: Effects on the development of staining for olfactory bulb succinate dehydrogenase and cytochromc oxidase. Dev. Brain Res. 35: 35-42.

Cuschieri, A., and L. H. Bannister (1975) The development of the olfactory mucosa in the mouse: Electron microscopy. J. Anat. 119: 471-498.

Farbman, A. I., and F. L. Margolis (1980) Olfactory marker protein during ontogeny: Immunohistochemical localization. Dev. Biol. 74: 205-215.

Farbman, A. I., and L. M. Squinto (1985) Early development of olfactory receptor cell axons. Dev. Brain Res. 19: 205-213.

Farbman, A. I., S. M. Ritz, and P. Brunjes (1984) The effect of odor deprivation on olfactory epithelium in developing rats. Soc. Neurosci. Abstr. 10: 530.

Graziadei, P. P. C., and G. A. Monti Graziadei (1978) Continuous nerve cell renewal in the olfactory system. In Handbook of Sensory Physiology, Vol. 9, M. Jacobson, ed., pp. 55-83, Springer-Verlag, Berlin.

Hilding, A. (1932) Experimental surgery of the nose and sinuses. I. Changes in the morphology of the epithelium following variations in ventilation. Arch. Otolaryngol. 16: 9-18.

Hinds, J. W., P. Hinds, and N. A. McNelly (1984) An autoradiographic study of the mouse olfactory epithelium: Evidence for long-lived receptors. Anat. Rec. 210: 375-383.

Kosaka, T., K. Kosaka, K. Hama, J.-Y. Wu, and I. Nagatsu (1987) Differential effect of functional olfactory deprivation on the GABAergic and catecholaminergic traits in the rat main olfactory bulb. Brain Res. 413: 197-203.

Meisami, E. (1976) Effects of olfactory deprivation on postnatal growth of the rat olfactory bulb utilizing a new method for production of neonatal unilateral anosmia. Brain Res. 107: 437-444.

Meisami, E., and R. Mousavi (1982) Lasting effects of early olfactory deprivation on the growth, DNA, RNA and protein content, and NaK-ATPase and AChE activity of the rat olfactory bulb. Dev. Brain Res. 2: 217-229.

Meisami, E., and L. Safari (1981) A quantitative study of the effects of early unilateral olfactory deprivation on the number and distribution of mitral and tufted cells and of glomeruli in the rat olfactory bulb. Brain Res. 221: 81-107.

Menco, B. P. M., and A. I. Farbman (1985) Genesis of cilia and microvilli of rat nasal epithelia during pre-natal development. I. O1factory epithelium, qualitative studies. J. Cell Sci. 78: 283-310.

Miragall, F., and G. A. Monti Graziadei (1982) Experimental studies on the olfactory marker protein. II. Appearance of the olfactory marker protein during differentiation of the olfactory sensory neurons of mouse: An immunohistochemical and autoradiographic study. Brain Res. 239: 245-250.

Mogensen, C., and M. Tos (1978) Experimental surgery on the nose. I. Airflow and goblet cell density. Acta Otolaryngol. 86: 289-297.

Monti Graziadei, G. A., R. S. Stanley, and P. P. C. Graziadei (1980) The olfactory marker protein in the olfactory system of the mouse during development. Neuroscience 5: 1239-1252.

Skeen, L. C., B. R. Due, and F. E. Douglas (1985) Effects of early anosmia on two classes of granule cells in developing mouse olfactory bulbs. Neurosci. Lett. 54: 301-306.

Skeen, L. C., B. R. Due, and F. E. Douglas (1986) Neonatal sensory deprivation reduces tufted cell number in mouse olfactory bulbs. Neurosci. Lett. 63: 5-10.

Sternberger, L. (1977) Immunocytochemistry, Prentice-Hall, Englewood Cliffs, NJ. 